\title{
Effect of Naphthalene Acetic Acid on the Adventitious Rooting in Shoot Cuttings of Andrographis paniculata (Burm.f.) Wall. ex Nees: An Important Therapeutical Herb
}

\author{
Md. Sanower Hossain and Zannat Urbi \\ Department of Biotechnology, Kulliyyah of Science, International Islamic University Malaysia, 25200 Kuantan, Pahang, Malaysia \\ Correspondence should be addressed to Md. Sanower Hossain; mshossainbge@gmail.com
}

Received 31 October 2015; Revised 12 February 2016; Accepted 23 February 2016

Academic Editor: Kent Burkey

Copyright (C) 2016 Md. S. Hossain and Z. Urbi. This is an open access article distributed under the Creative Commons Attribution License, which permits unrestricted use, distribution, and reproduction in any medium, provided the original work is properly cited.

\begin{abstract}
Andrographis paniculata is one of the most important therapeutical herbs, widely used in traditional medical systems for the treatment of diverse diseases for thousands of years. This study was carried out to assess the effect of 1-naphthaleneacetic acid (NAA) on adventitious rooting in A. paniculata shoot cuttings. The cuttings were treated with six concentrations of NAA (0.5, 1.0, $1.5,2.0,2.5$, and $3.0 \mathrm{mM}$ ) by applying soaking method and cuttings without hormone (soaking in distilled water) were considered as control. The cuttings were then inoculated into peat moss in the planting tray and incubated under complete shade for root induction. Water was sprayed on peat moss once daily to moisten it. The results showed that different concentrations of NAA significantly $(P \leq 0.05)$ affected the rooting characteristics of $A$. paniculata and $2.5 \mathrm{mM}$ of NAA was found to be more effective to induce rooting in young apical shoot (YAS) cuttings compared to other concentrations and old apical shoot (OAS). This study also postulates that adventitious rooting response depends on the juvenility of plant material and concentration of growth regulator. This report describes a technique for adventitious rooting in A. paniculata, which could be feasible to use for commercial scale propagation of this plant.
\end{abstract}

\section{Introduction}

Medicinal plants are moving from fringe to mainstream uses. Nowadays, medicinal plants are being investigated extensively worldwide to find alternative remedies and health approaches free from side effects caused by synthetic chemicals [1]. Moreover, the indication of healing power of plants to cure diseases and their importance depicted in the religious books also highly motivated people to take natural remedy as well as researchers to study their pharmacology [2]. Andrographis paniculata (Burm.f.) Wall. ex Nees from the Acanthaceae family is one of the highly potential therapeutical herbs traditionally used for the treatment of diverse diseases such as cancer, diabetes, high blood pressure, ulcer, leprosy, bronchitis, skin diseases, flatulence, colic, influenza, dysentery, dyspepsia, and malaria for thousands of years [3]. It is widely found over a broad ecogeographical range in tropical Asian countries. A. paniculata has a broad spectrum of pharmacological effects such as hepatoprotective, antihyperglycemic, antihypertensive, antimicrobial, anti-inflammatory, antipyretic, anti-HIV, anti-H1N1, anticancer, and antihepatitis effects [3]. This plant possesses more than 55 ent-labdane diterpenoids, 30 flavonoids, 8 quinic acids, 4 xanthones, and 5 rare noriridoids, of which 46 showed unique and interesting pharmacological effects [3]. Nowadays, this plant is in high demand and its extract and bioactive compound (andrographolide) have been commercialized. For example, KalmCold ${ }^{\mathrm{TM}}$ is a commercially available product of A. paniculata extract, which is used for the patients with uncomplicated upper respiratory tract infection. The efficacy of this product has been proven through randomized double blind placebo controlled clinical evaluation where they found 2.1 times or $52.7 \%$ higher effectiveness than placebo [4]. Moreover, good quality dried leaves cost US $\$ 5.0$ per $\mathrm{kg}$ and the purified andrographolide from specialist chemical suppliers could be sold for as much as US\$100,000 per kg 
[3]. Considering the high medicinal and commercial value, this plant needs to be grown commercially to meet the high industrial demand.

The propagation of $A$. paniculata generally occurs through shattered seeds in nature. However, seed dormancy is a major constrain in A. paniculata propagation for commercial purposes and detailed agronomic study is also extremely lacking [3]. Moreover, conventional propagation of A. paniculata via seeds is curbed due to variability among the seed-derived progenies and scanty and delayed rooting of seedlings [5]. Therefore, finding an alternate way for commercial scale propagation of this plant would be effective to meet the commercially required quantity.

Vegetative propagation through cutting is extensively used in agriculture, horticulture, and forestry for mass-multiplication of economically important plants selected from natural populations or obtained in breeding programs [6]. The proper formation of adventitious rooting at the base of shoot cuttings is an essential step for the successful vegetative propagation. This process involves the initiation of several new meristematic areas in different tissues of shoot cuttings [7]. The process is regulated by external (e.g., temperature, light, medium, and mineral salts) and internal factors (e.g., hormones, especially auxin, carbohydrates, and other molecules) [8]. Normal cuttings without treatment of plant growth regulators (PGRs) are difficult and usually take long time. PGRs have direct (i.e., involved in cell division or cell growth) or indirect (i.e., interacting with other hormones or molecules) effects on plants. Haissig and Davis [9] introduced new rooting treatments and examined the effects of PGRs by a short exposure to a solution with a high concentration of auxin or by dipping in rooting powder. Auxin is widely applied in the vegetative propagation of various plants $[10,11]$, and there are many deviations in the range of effectiveness of 1-naphthaleneacetic acid (NAA) dosages on cuttings of different plant species [12]. Most of the studies reported in the past on the adventitious rooting in medicinal plants and woody plants were mainly focused on Indole-3-butyric acid (IBA), while other auxins (i.e., Indole-3-acetic acid (IAA) and NAA) received less consideration. In 2011, Raji and Osman [13] showed that hormonal factors greatly influence the adventitious rooting in Stevia rebaudiana, a commercially important sweetening medicinal herb and higher concentration $(2.3 \mathrm{mM})$ of IBA induces maximum number of roots within short time. In another study, Azad and Matin [14] concluded that the use of $0.4 \%$ IBA for rooting in juvenile leafy branch cutting of Swietenia macrophylla would be effective for mass propagation. Yan et al. [12] investigated significant role of NAA in the adventitious rooting in Hemarthria compressa. In the comparative study of the role of different auxins in Saraca asoka for the root development, IBA showed more positive response on rooting as compared to IAA and NAA within 4 weeks of transfer to growing medium under mist condition [8]. Auxin synthesized mainly in young leaves plays a major role in controlling growth and development of plants, early stages of embryogenesis, organization of apical meristem (phyllotaxy) and branching of the plant aerial parts (apical dominance), formation of main root, and lateral and adventitious root initiation by active transportation to other tissues [6]. Since the effectiveness of auxin varies species to species and rooting success differs with different concentrations of individual auxins [15-17], in this study we focused on NAA and in the consecutive study other auxins will be investigated. In addition, age of the plant is also an important influential factor over the rooting ability of cuttings and usually juvenile cuttings showed greater success in rooting [18-20].

Although there are many in vitro studies demonstrating the effect of auxin in in vitro regenerated plants by adding micromole of auxin in the medium [5,20-24], to date to our knowledge, no study has been conducted in A. paniculata using soaking method in high concentration of PGR. Therefore, the present study was conducted to assess the effect of NAA on adventitious rooting in shoot cuttings of $A$. paniculata with the aim of fastening the cultivation process.

\section{Materials and Methods}

2.1. Plant Materials and Treatments. The apical shoots of $A$. paniculata were selected from five different individuals each of younger plants around 2-3 months old (YAS) and older plants around 8 months old (OAS). The YAS and OAS cuttings of 4-6 cm length with 3 nodes and 6-8 leaves were obtained from vigorously growing $A$. paniculata off flowering stage. The cuttings were slant cut (approximately $45^{\circ}$ ) and were rinsed with distilled water for few minutes to remove external dust. The basal ends $(\sim 1 \mathrm{~cm})$ of each cutting were then soaked in different concentrations $(0,0.5,1.0,1.5,2.0$, 2.5 , and $3.0 \mathrm{mM}$ ) of NAA for 4 seconds. The cuttings without NAA were considered as control. After soaking, the cuttings were allowed for 10 minutes before finally being transferred to planting tray. There were three replicates from both YAS and OAS for each treatment and the experiment was repeated twice. The treated cuttings were then inoculated immediately into peat moss (Peltacom, Poland) in the planting tray (well dimension $3.25 \times 4.5$ ). The trays were then incubated under complete shade for root induction for 15 days. The recorded temperature was $25 \pm 2^{\circ} \mathrm{C}$ and relative humidity was $80 \pm$ $5 \%$. Water was sprayed to moisten peat moss once daily. After recording data, the cuttings were transferred to poly bags containing garden top soil. The plants were under observation until full maturity and irrigated water once daily, and fertilizer was used biweekly.

2.2. Data Scoring. The induction of rooting was observed daily from day 3 onwards. The observation of rooting was done carefully by using forceps to lift up peat moss at a lower level below the depth of insertion of cuttings. After counting first day of rooting, the cuttings were returned back into the peat moss carefully to prevent injury of the tissue. Finally, rooting percentage, numbers of adventitious roots per cuttings, and length of roots were recorded on day 15 . The average rooting time (days) of each concentration was also calculated to assess the fastest root induction effect of NAA concentration.

2.3. Statistical Analysis. The experiment was completely randomized block design and each experiment was repeated 
TABLE 1: Rooting response in young and old apical shoot cuttings of $A$. paniculata under treatment of NAA dosages.

\begin{tabular}{lcccc}
\hline \multirow{2}{*}{ NAA $(\mathrm{mM})$} & \multicolumn{2}{c}{ YAS } & \multicolumn{2}{c}{ OAS } \\
& Duration of rooting (day) & Length of roots $(\mathrm{cm})$ & Duration of rooting (day) & Length of roots $(\mathrm{cm})$ \\
\hline 0 & $11.17 \pm 0.30^{\mathrm{a}}$ & $1.61 \pm 0.15^{\mathrm{x}}$ & $10.83 \pm 0.47^{\mathrm{a}}$ & $1.12 \pm 0.1^{\mathrm{xu}}$ \\
0.5 & $9.17 \pm 0.70^{\mathrm{ab}}$ & $1.52 \pm 0.26^{\mathrm{xvt}}$ & $10.33 \pm 0.88^{\mathrm{a}}$ & $1.67 \pm 0.22^{\mathrm{xzuw}}$ \\
1.0 & $9.00 \pm 1.18^{\mathrm{ab}}$ & $2.53 \pm 0.42^{\mathrm{xyzv}}$ & $9.00 \pm 0.52^{\mathrm{a}}$ & $2.11 \pm 0.15^{\mathrm{yz}}$ \\
1.5 & $8.17 \pm 0.48^{\mathrm{ab}}$ & $2.77 \pm 0.20^{\mathrm{zt}}$ & $12.00 \pm 0.68^{\mathrm{a}}$ & $1.16 \pm 0.14^{\mathrm{xu}}$ \\
2.0 & $10.16 \pm 0.54^{\mathrm{ac}}$ & $1.65 \pm 0.17^{\mathrm{xvr}}$ & $10.50 \pm 0.62^{\mathrm{a}}$ & $1.2 \pm 0.19^{\mathrm{xy}}$ \\
2.5 & $7.83 \pm 0.48^{\mathrm{bc}}$ & $3.31 \pm 0.26^{\mathrm{yw}}$ & $10.00 \pm 0.63^{\mathrm{a}}$ & $1.18 \pm 0.12^{\mathrm{xv}}$ \\
3.0 & $8.17 \pm 0.30^{\mathrm{bc}}$ & $1.47 \pm 0.11^{\mathrm{v}}$ & $9.50 \pm 0.22^{\mathrm{a}}$ & $3.29 \pm 0.28^{\mathrm{y}}$ \\
\hline
\end{tabular}

Values within a column followed by different letters indicate significant differences among treatments of different concentrations of NAA at $P \leq 0.05$ of GamesHowell test $(n=6)$. Each value represents a mean \pm standard error of mean.

twice. Means of 6 replicates for each concentration were calculated. All data were analyzed using one-way analysis of variance (ANOVA) and the Games-Howell test at $P \leq 0.05$ for comparisons among NAA dosages using the PASW Statistics 18 (SPSS Inc., Chicago).

\section{Results}

The present investigations revealed a significant influence of different concentrations of NAA on adventitious root development in shoot cuttings of $A$. paniculata compared to control after 15 days (Table 1, Figure 1). The responses of YAS and OAS cuttings differed significantly in terms of duration of rooting, number of adventitious roots per cutting, and length of roots. The present study showed that, with the increasing concentrations of NAA, the responses of rooting characteristics in terms of number of roots/explant were increased up to the highest concentration of NAA for YAS (Figure 1), but rooting time and length of root $(3.31 \mathrm{~cm})$ were the best at $2.5 \mathrm{mM}$ of NAA (Table 1, Figure 2(b)), and higher concentrations suppressed these s). On the other hand, OAS cuttings showed longest roots at $3.0 \mathrm{mM}$ of NAA and root length decreased significantly at lower dosages (Table 1 ). The rooting time for OAS was statistically insignificant in all dosages of NAA; however, $1.0 \mathrm{mM}$ of NAA produces roots comparatively faster. Average number of roots/explant was highest at $2.5 \mathrm{mM}$ of NAA (Figure 2(c)). In all cases, the rooting was highly successful and the response of root induction was $100 \%$.

In comparison to YAS with OAS, it can be concluded that YAS showed the most rapid response at $2.5 \mathrm{mM}$ of NAA (7.83 days) compared to OAS, which showed the quickest responses to $1.0 \mathrm{mM}$ of NAA at day 9. This indicates that high dosages were more efficient for rapid rooting in YAS and low dosages were more effective for fast rooting in OAS. However, for number of roots/explants and root length characteristics, higher dosages were highly effective for both YAS and OAS. YAS produced a maximum of 25.33 roots/explant at $3.0 \mathrm{mM}$ of NAA and OAS induced a maximum 20.33 roots/explant at $2.5 \mathrm{mM}$ of NAA. In addition, total number of roots/explant was significantly reduced to 13.17 roots at $3.0 \mathrm{mM}$ of NAA for OAS. Similarly, YAS induced the longest roots $(3.31 \mathrm{~cm})$ at $2.5 \mathrm{mM}$ of NAA and OAS produced $3.29 \mathrm{~cm}$ roots at $3.0 \mathrm{mM}$

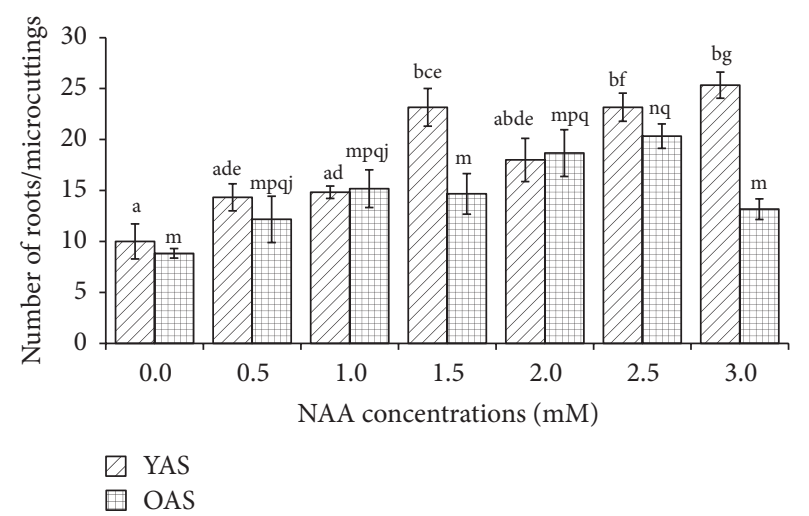

Figure 1: Effect of NAA in adventitious root development in $A$. paniculata. YAS = young apical shoot microcutting and OAS = old apical shoot microcutting. Different letters indicate the significant difference among the treatment of different concentrations of NAA at $P \leq 0.05$ of Games-Howell test $(n=6)$. Each value represents a mean \pm standard error of mean.

of NAA. Overall, YAS was the most efficient to induce roots at the higher concentration of NAA.

After 15 days of inoculation, all rooted plantlets were transferred to poly bags and successfully grown under field condition (Figure 2(d)). The observation was continued until the full maturity of the plants (Figure 2(e)) and we did not observe any deleterious morphology or death of plants over the 2-3-month-observation periods. However, in visual inspection, the growth and development of all plants were not similar.

\section{Discussion}

The objective of this study was to evaluate the effect of NAA on adventitious rooting in shoot cuttings of $A$. paniculata. We observed that adventitious root formation was influenced by NAA greatly on adventitious rooting in shoot cuttings obtained from young and old plants, but the value of rooting characteristics was higher for the YAS cuttings than the OAS cuttings. This may happen because the YAS cuttings were 


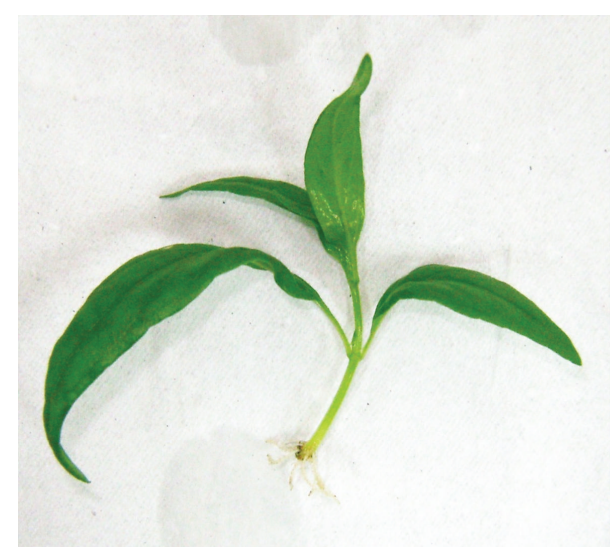

(a)

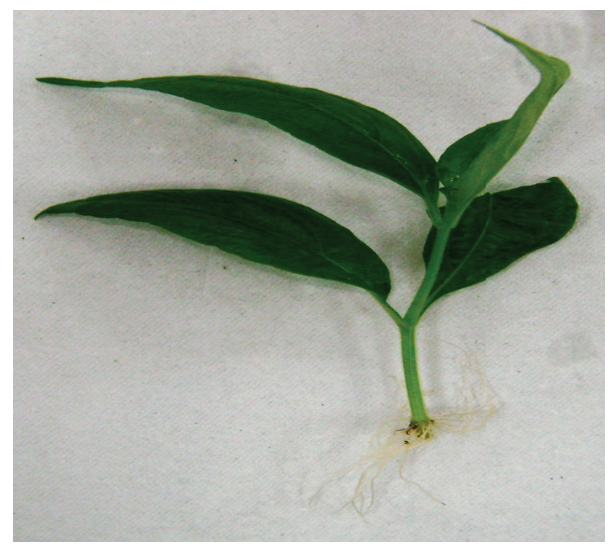

(c)

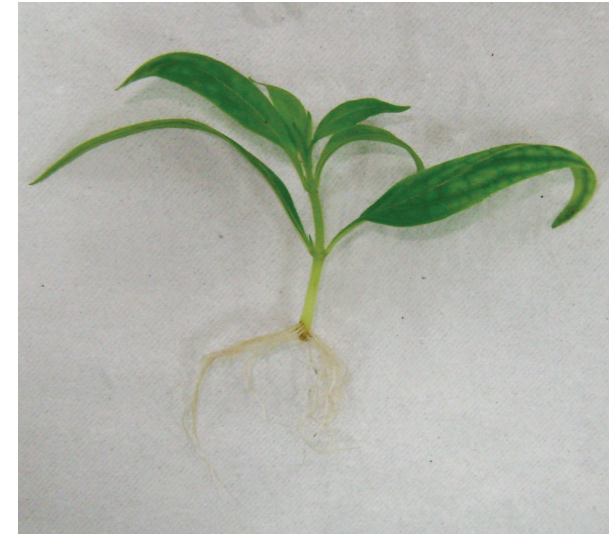

(b)

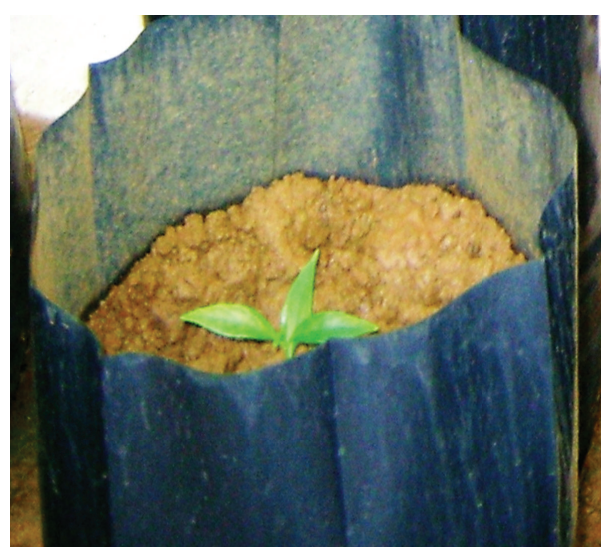

(d)

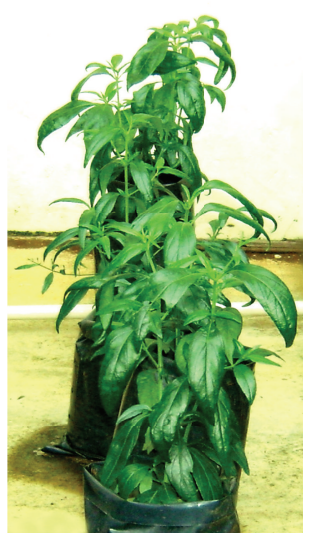

(e)

FIGURE 2: Representative photos of rooted plantlets: (a) control group, (b) $2.5 \mathrm{mM}$ NAA treated young apical shoot microcutting, (c) 3.0 mM NAA treated old apical shoot microcutting, (d) hardening in poly bag, and (e) representative photos of matured plants grown in poly bags placed in the field under partial shade.

more responsive to external treatment of NAA, which stimulates root development. Moreover, the rooting ability of cuttings varied among clones, node positions, and plant maturity [12].

Adventitious rooting system is a high energy requiring process that requires more reserve of food material for root initiation. Because, this system involves cell division, in which predetermined cells turn to mother cells for the root primordia by following morphogenetic pathways [25]. Besides reserve food material, plant growth regulators such as auxin (i.e., IBA, IAA, and NAA) play an important role in adventitious rooting as well as growth and morphological diversity in plants $[26,27]$. Although the endogenous auxin level has great influence on root induction, application of plant growth regulators significantly increases either low or high concentration of auxin. The applied auxin increases the concentration of endogenous auxin and accumulates itself in the basal region of the cuttings, which act as a metabolizing agent that induces signal for rooting [28]. For example, Yan et al. [12] reported that lower level of NAA significantly increased the adventitious rooting in Hemarthria compressa; however, in our study we observed that higher concentration of NAA resulted in an increased number of adventitious rooting per cutting (Figure 1). Similarly, Raji and Osman [13] and Dash et al. [8] reported that higher dosages of auxins induced increased number of roots within a short time. In developing stage, the endogenous auxin was increased compared to other stages. In this study, we investigated the quick responses of adventitious rooting in YAS compared to OAS cuttings (Table 1); the results indicate that the treatment of auxin influenced more the root induction in young plants than the old ones. Our result was also in agreement with Kibbler et al. [29] who reported that the rooting potential of the cuttings is a juvenile characteristic that decreases after maturation, resulting in reduced capacity to induce rooting in mature shoot cuttings.

Of the NAA dosages tested, higher dosages caused a significant increase in adventitious rooting ability in YAS cuttings as compared with OAS (Figure 1). The treatment of $3.0 \mathrm{mM}$ NAA was found to be the best at enhancing rooting ability in YAS. However, the dosage $2.5 \mathrm{mM}$ of NAA induced the highest number of adventitious roots in OAS instead of $3.0 \mathrm{mM}$ (Figure 1), which supports the theory of Hentig and Grüber 
[30] who reported that hormonal dosages could induce the best rooting when just below the toxic level. In several in vitro studies on adventitious rooting during micropropagation of A. paniculata, higher concentrations of auxin were found to be more effective in adventitious rooting in microshoots $[21,22]$. Moreover, plant growth hormones also have effects on cell elongation and cell division thereby boosting root length, thus enhancing overall growth of cuttings [31].

In the present study, we also found adventitious rooting response in control treatment over the 15-day observation, but it was less effective for further growth of plantlets. The production of roots in the control group may be caused by endogenous auxin, which might influence and play important role for root primordia formation in the cuttings. Ascough et al. [32] reported that adventitious rooting was best in the control group compared to NAA and IAA treatment in Sisyrinchium laxum. The key importance of our study is that this technique is very simple, easy, less expensive, and very rapid. Moreover, no experience is required which is a compulsory factor for plant tissue culture for large scale propagation. To skip the high cost and contamination problem in in vitro study, this method could be applicable for commercial scale cultivation as an alternative.

\section{Conclusion}

In this study, it is found that YAS is more competent to induce roots compared to OAS and $2.5 \mathrm{mM}$ of NAA is highly effective in increasing root formation in A. paniculata shoot cuttings of young plants. This study also shows that adventitious rooting response to PGR in a juvenility of plant and a concentration dependent manner. Considering the overall results, it is suggested that $2.5 \mathrm{mM}$ of NAA could be used for commercial scale production of this commercially and medicinally important herb, A. paniculata. High dosages of NAA should be employed for mature plant if juvenile plant is not available. Further study may be conducted to examine the effect of other auxins such as IBA and IAA on rooting in $A$. paniculata shoot cuttings as well as duration of soaking since it has significant effect on adventitious rooting [12] and substrate type.

\section{Competing Interests}

The authors have no conflict of interests regarding publishing this paper.

\section{Acknowledgments}

The authors express their gratefulness to Dr. Abdullateef Akintunde Raji, Kulliyyah of Science, International Islamic University Malaysia, for his assistance and suggestions in designing the experiment of this study. At present, Dr. Raji is a lecturer in the Biological Science and Biotechnology Department, Kwara State University, Malete, Nigeria. The authors are also thankful to Mr. Mohammad Ibrahim Auli Ullah, Universiti Sultan Zainal Abidin, Kuala Terengganu, Malaysia, for his critical proof reading of this paper.

\section{References}

[1] H. N. Shivaprasad, "Expectations of natural/herbal products industry," in Proceedings of the International Conclave on Medicinal Plants for ASEAN and BIMSTEC Countries, pp. 78-82, Jubilee Hall RIMS Campus, December 2008.

[2] Z. Urbi, M. S. Hossain, K. M. H. Rahman, and T. M. Zayed, "Grape: a medicinal fruit species in the holy Qur'an and its ethnomedicinal importance," World Applied Sciences Journal, vol. 30, no. 3, pp. 253-265, 2014.

[3] M. S. Hossain, Z. Urbi, A. Sule, and K. M. H. Rahman, "Andrographis paniculata (Burm. f.) Wall. ex Nees: a review of ethnobotany, phytochemistry, and pharmacology," The Scientific World Journal, vol. 2014, Article ID 274905, 28 pages, 2014.

[4] R. C. Saxena, R. Singh, P. Kumar et al., "A randomized double blind placebo controlled clinical evaluation of extract of Andrographis paniculata (KalmCold ${ }^{\mathrm{TM}}$ ) in patients with uncomplicated upper respiratory tract infection," Phytomedicine, vol. 17, no. 3-4, pp. 178-185, 2010.

[5] K. P. Martin, "Plant regeneration protocol of medicinally important Andrographis paniculata (Burm. f.) Wallich ex Nees via somatic embryogenesis," In Vitro Cellular \& Developmental Biology-Plant, vol. 40, no. 2, pp. 204-209, 2004.

[6] T. I. Pop, D. Pamfil, and C. Bellini, "Auxin control in the formation of adventitious roots," Notulae Botanicae Horti Agrobotanici Cluj-Napoca, vol. 39, no. 1, pp. 307-316, 2011.

[7] S. Kaur, S. S. Cheema, B. R. Chhabra, and K. K. Talwar, "Chemical induction of physiological changes during adventitious root formation and bud break in grapevine cuttings," Plant Growth Regulation, vol. 37, no. 1, pp. 63-68, 2002.

[8] G. K. Dash, S. K. Senapati, and G. R. Rout, "Effect of auxins on adventitious root development from nodal cuttings of Saraca asoka (Roxb.) de Wilde and associated biochemical changes," Journal of Horticulture and Forestry, vol. 3, no. 10, pp. 320-326, 2011.

[9] B. E. Haissig and T. D. Davis, "A historical evaluation of adventitious rooting research to 1993," in Biology of Adventitious Root Formation, T. D. Davis and B. E. Haissig, Eds., pp. 275-331, Plenum Press, New York, NY, USA, 1994.

[10] R. W. Hunt, S. Chinnasamy, A. Bhatnagar, and K. C. Das, "Effect of biochemical stimulants on biomass productivity and metabolite content of the microalga, Chlorella sorokiniana," Applied Biochemistry and Biotechnology, vol. 162, no. 8, pp. 2400-2414, 2010.

[11] A. Husen and M. Pal, "Variation in shoot anatomy and rooting behaviour of stem cuttings in relation to age of donor plants in teak (Tectona grandis Linn. f.)," New Forests, vol. 31, no. 1, pp. 57-73, 2006.

[12] Y.-H. Yan, J.-L. Li, X.-Q. Zhang et al., "Effect of naphthalene acetic acid on adventitious root development and associated physiological changes in stem cutting of Hemarthria compressa," PLoS ONE, vol. 9, no. 3, Article ID e90700, 2014.

[13] A. A. Raji and M. Osman, "Effects of stem cutting types, position and hormonal factors on rooting in Stevia rebaudiana Bertoni," Journal of Agricultural Science, vol. 4, no. 1, pp. 49-57, 2012.

[14] M. S. Azad and M. A. Matin, "Effect of indole-3-butyric acid on clonal propagation of swietenia macrophylla through branch cutting," Journal of Botany, vol. 2015, Article ID 249308, 7 pages, 2015.

[15] R. R. B. Leakey, J. F. Mesen, Z. Tchoundjeu et al., "Lowtechnology techniques for the vegetative propagation of tropical 
trees," Commonwealth Forestry Review, vol. 69, no. 3, pp. 247257, 1990.

[16] R. R. B. Leakey, A. C. Newton, and J. M. P. Dick, "Captureof genetic variation by vegetative propagation: processes determining success," in Tropical Trees: The Potential for Domestication and the Rebuilding of Forest Resources, R. R. B. Leakey and A. C. Newton, Eds., pp. 72-83, HMSO, London, UK, 1994.

[17] Z. Tchoundjeu, M. L. Avana, R. R. B. Leakey et al., "Vegetative propagation of Prunus africana: effects of rooting medium, auxin concentrations and leaf area," Agroforestry Systems, vol. 54, no. 3, pp. 183-192, 2002.

[18] E. Opuni-Frimpong, D. F. Karnosky, A. J. Storer, and J. R. Cobbinah, "Key roles of leaves, stockplant age, and auxin concentration in vegetative propagation of two African mahoganies: Khaya anthotheca Welw. and Khaya ivorensis A. Chev," New Forests, vol. 36, no. 2, pp. 115-123, 2008.

[19] E. Amri, H. V. M. Lyaruu, A. S. Nyomora, and Z. L. Kanyeka, "Vegetative propagation of African Blackwood (Dalbergia melanoxylon Guill. \& Perr.): effects of age of donor plant, IBA treatment and cutting position on rooting ability of stem cuttings," New Forests, vol. 39, no. 2, pp. 183-194, 2010.

[20] B. Singh, R. Yadav, and B. P. Bhatt, "Effects of mother tree ages, different rooting mediums, light conditions and auxin treatments on rooting behaviour of Dalbergia sissoo branch cuttings," Journal of Forestry Research, vol. 22, no. 1, pp. 53-57, 2011.

[21] V. S. Dandin and H. N. Murthy, "Regeneration of Andrographis paniculata Nees: analysis of genetic fidelity and andrographolide content in micropropagated plants," African Journal of Biotechnology, vol. 11, no. 61, pp. 12464-12471, 2012.

[22] J. Purkayastha, T. Sugla, A. Paul, S. Solleti, and L. Sahoo, "Rapid in vitro multiplication and plant regeneration from nodal explants of Andrographis paniculata: a valuable medicinal plant," In Vitro Cellular and Developmental Biology - Plant, vol. 44, no. 5, pp. 442-447, 2008.

[23] N. Praveen, S. H. Manohar, P. M. Naik, A. Nayeem, J. H. Jeong, and H. N. Murthy, "Production of andrographolide from adventitious root cultures of Andrographis paniculata," Current Science, vol. 96, no. 5, pp. 694-697, 2009.

[24] A. Kataky and P. Handique, "Micropropagation and screening of antioxidant potential of Andrographis paniculata (Burm. f) Nees," Journal of Hill Agriculture, vol. 1, no. 1, pp. 13-18, 2010.

[25] R. A. Aeschbacher, J. W. Schiefelbein, and P. N. Benfey, "The genetic and molecular basis of root development," Annual Review of Plant Physiology and Plant Molecular Biology, vol. 45, no. 1, pp. 25-45, 1994.

[26] O.-T. Kim, M.-Y. Kim, S.-M. Huh, J.-C. Ahn, N.-S. Seong, and B. Hwang, "Effect of growth regulators on asiaticoside production in whole plant cultures of Centella asiatica (L.) urban," Journal of Plant Biology, vol. 47, no. 4, pp. 361-365, 2004.

[27] J. L. Eun, M. Mobin, J. H. Eun, and Y. P. Kee, "Effects of sucrose, inoculum density, auxins, and aeration volume on cell growth of Gymnema sylvestre," Journal of Plant Biology, vol. 49, no. 6, pp. 427-431, 2006.

[28] A. Husen, "Clonal propagation of Dalbergia sissoo Roxb. and associated metabolic changes during adventitious root primordium development," New Forests, vol. 36, no. 1, pp. 13-27, 2008.

[29] H. Kibbler, M. E. Johnston, and R. R. Williams, "Adventitious root formation in cuttings of Backhousia citriodora F. Muell: 1. Plant genotype, juvenility and characteristics of cuttings," Scientia Horticulturae, vol. 102, no. 1, pp. 133-143, 2004.
[30] W. Hentig and G. Grüber, "Influence of rooting hormones on the propagation of several 'new' ornamentals," Acta Horticulturae, vol. 266, pp. 479-488, 1987.

[31] M. Abidin and A. Baker, "Effect of growth substances on rooting of cocoa cuttings," Acta Horticulturae, vol. 137, pp. 95-102, 1984.

[32] G. D. Ascough, P. A. Swart, J. F. Finnie, and J. Van Staden, "Micropropagation of Romulea minutiflora, Sisyrinchium laxum and Tritonia gladiolaris_-iridaceae with ornamental potential," South African Journal of Botany, vol. 77, no. 1, pp. 216-221, 2011. 


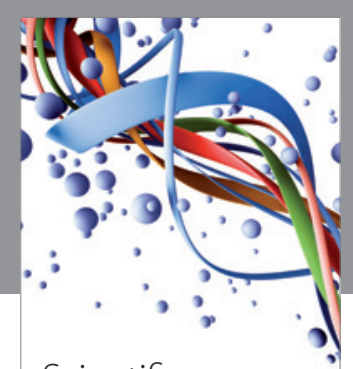

Scientifica
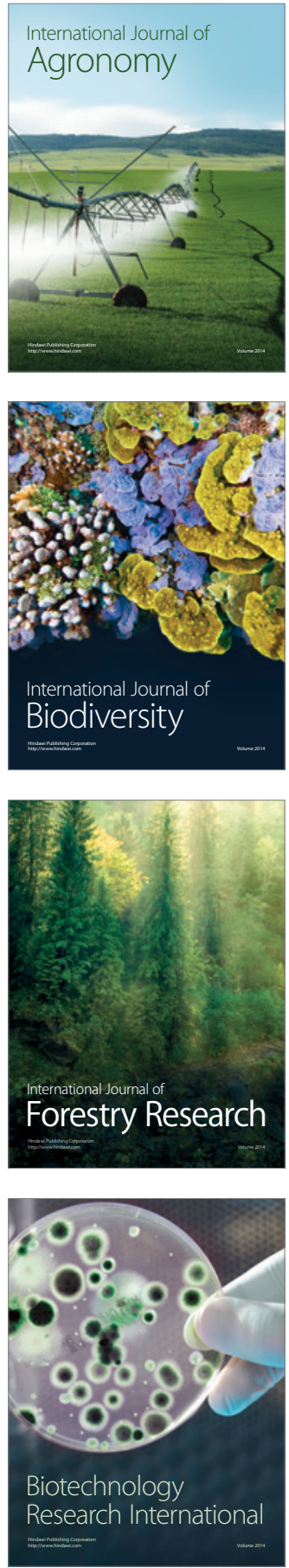
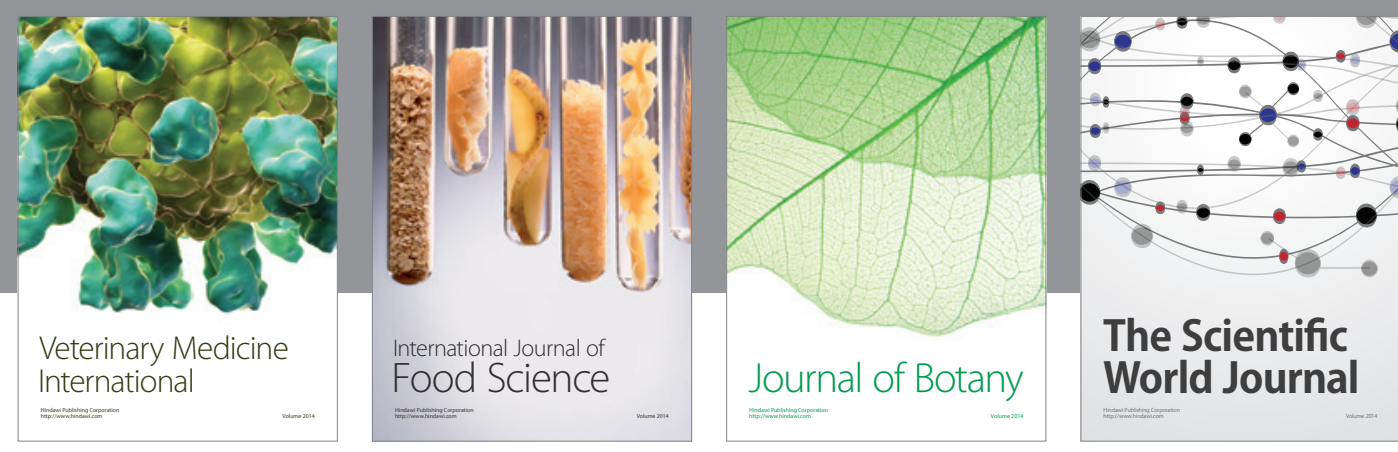

The Scientific

\section{World Journal}

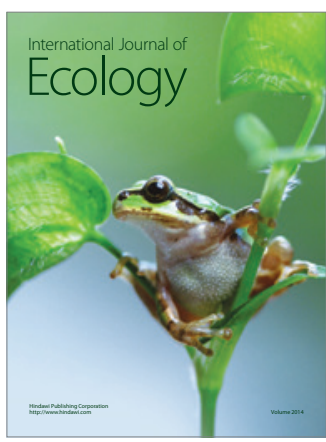

\section{Hindawi}

Submit your manuscripts at

http://www.hindawi.com
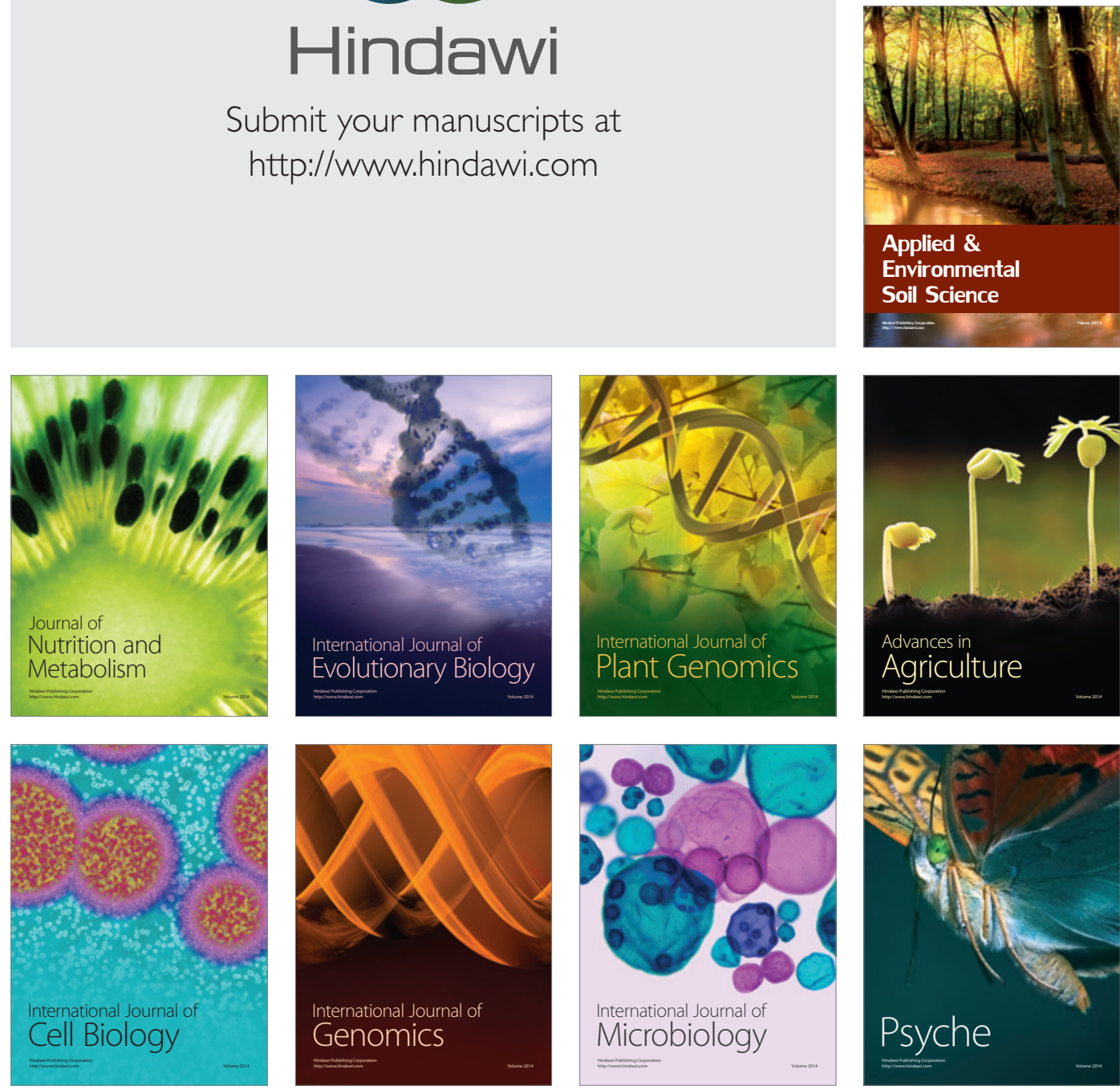
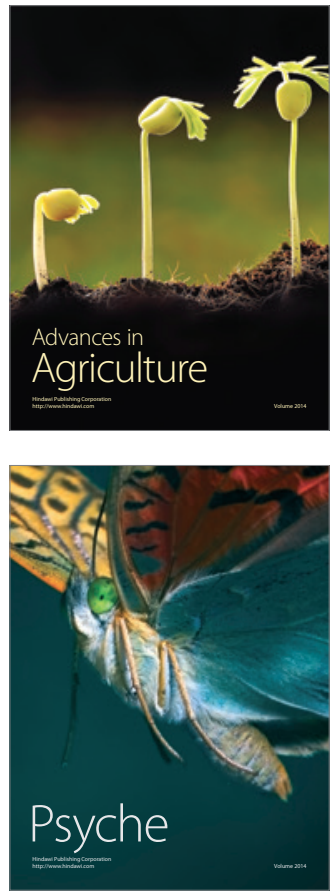